\title{
A METrópole PAULista e A SAÚde
}

\author{
Aylene Bousouat \\ Médica, Professora da Faculdade de Medicina do ABC, Pesquisadora do Cedec \\ VÂNia Barbosa do Nascimento \\ Médica, Professora da Faculdade de Medicina do ABC, Pesquisadora do Cedec
}

\begin{abstract}
Resumo: O presente artigo procura abordar as características da Região Metropolitana de São Paulo em face do atual processo de reorganização do modelo de atenção à saúde no Brasil, no que se refere à ênfase atribuída ao poder local e à universalização do direito à saúde. Identifica-se neste contexto uma tensão ao configurar São Paulo como uma metrópole global, tendo como pano de fundo o fluxo da população em busca de serviços de atenção à saúde. Para isto, utilizou-se como parâmetro para a análise o fluxo estabelecido pela população da sub-região metropolitana sudeste, mais conhecida como a Região do ABC. Desenha-se assim um painel em que se confrontam duas tensões, ou melhor, duas escalas: a municipal e a metropolitana.

Palavras-chave: metrópole; políticas de saúde; serviços de saúde.
\end{abstract}

A Região Metropolitana de São Paulo ainda povoa o imaginário das pessoas como a metrópole industrial brasileira por excelência, um verdadeiro "gigante industrial". Essa imagem, entretanto, não é mais capaz de expressar a atual complexidade da metrópole paulista. As décadas de 80 e 90 assistiram a uma modificação radical da essência dessa região. Sem dúvida, um novo perfil passou a caracterizá-la, agora não mais como a metrópole industrial e sim como uma verdadeira metrópole global, transacional.

Esse fato traz implicações profundas à constituição dos direitos sociais, inclusive à garantia da saúde, quando se identifica a existência de um rápido processo de transição dos territórios urbanos, em que cada vez mais os espaços adquirem fluidez não respeitando os limites administrativos municipais, limites claramente definidos no atual processo de reorganização do modelo de atenção à saúde durante as décadas de 80 e 90 , pautados pela prioridade dada à esfera municipal.

Configura-se assim uma tensão, ao considerar que, por um lado, as atuais diretrizes políticas do setor saúde, em consonância com a redefinição do poder político-institucional no país, encontram-se favoráveis aos interesses descentralizadores e democráticos pela ênfase atribuída ao poder local e à universalização do direito à saúde. $\mathrm{E}$ por outro, ao configurar-se como uma metrópole global, São Paulo ganha novos atributos, podendo mesmo se afir- mar que o espaço se torna fluido - com uma intensa mobilidade de fatores de produção, trabalho, mercado, produtos, capital, serviços, entre outros (Santos, 1993a e b). O que inevitavelmente imprime sérias dificuldades ao acesso universal e equânime à saúde, quando pautados pela lógica municipal de gestão do sistema de atenção à saúde.

Os objetivos deste artigo consistem, portanto, em identificar essa tensão a partir de duas perspectivas. A primeira, pelas novas características de São Paulo, que a configuram como uma metrópole global, tendo como pano de fundo o fluxo da população em busca de serviços de saúde. A segunda, pela dinâmica intermunicipal de utilização de serviços de saúde da sub-região metropolitana sudeste, mais conhecida como a Região do Grande ABC. Desenha-se assim um painel onde são delineados dois aspectos: o municipal e o metropolitano, no interior de um mesmo contexto socioespacial. Considerando-se essas perspectivas de análise, agregam-se ao processo de atendimento das necessidades sociais novos elementos a serem incorporados nos possíveis arranjos organizacionais do modelo de atenção à saúde na Região Metropolitana de São Paulo.

\section{SÃO PAULO, UMA METRÓPOLE GLOBAL}

A incorporação de novas tecnologias, com ênfase na circulação de informações; o fenômeno da "involução metropolitana", no qual a metrópole cresce menos que a 
região; a especialização nos setores terciário e quaternário da economia; a diminuição relativa do peso industrial, associada à mudança nas características das plantas industriais que tendem a se tornar menores, automatizadas e não-poluentes; o aumento da economia e do emprego informal e o aumento das desigualdades e da pobreza são alguns dos elementos da transformação de São Paulo na metrópole global, transacional brasileira (Santos, 1994).

Ressalta-se que mais do que a simples substituição das características "típicas" das metrópoles industriais para as apontadas no parágrafo anterior, é, na verdade, estar diante da "nova forma espacial" da economia global e da sociedade informacional (Castells, 1999:428).

Se a fórmula de manutenção do poder da metrópole industrial era crescer sem parar - aumentando sua área de influência contígua; incrementando o número de plantas industriais e de serviços; atraindo populações migrantes, etc. - , o mesmo não ocorre no caso da metrópole transacional. Nesse caso, como a informação é a peça-chave desse processo, a metrópole transacional, dentro desse espaço fluido, não precisa necessariamente agregar todos os elementos em seu território, e mesmo assim é possível manter o comando e a direção política e econômica.

Outro aspecto central no processo de conformação da metrópole transacional paulista é estar marcado pela "intensificação e renovação dos processos sociais de exclusão (...). Em outros termos, as novas feições da paisagem e a intensificação da exclusão social estão presentes nas metrópoles contemporâneas". Desse modo, a dimensão espacial da exclusão social passa a ser outro elemento que deve ser incorporado na perspectiva da construção de políticas de saúde que perseguem a eqüidade (Lencioni, 1996:40, grifo nosso).

Em suma, se as grandes metrópoles mudaram muito, o espaço virou fluxo, somaram-se informações às mercadorias circulando por estradas, mercadorias não-palpáveis circulando pelo ar, uma cidade cada vez mais desigual se consolidou, e pessoas se apropriaram cada vez mais diferentemente dos seus territórios, aí está caracterizada uma mudança radical que precisa ser entendida pelo campo de estudo das políticas da saúde.

\section{A Nova Configuração do Espaço Produtivo e as Implicações para as Políticas de Saúde}

A concentração de atividades econômicas, particularmente industriais, pode ser considerada, até a década de 70, o eixo organizador da cidade de São Paulo e de sua região metropolitana, que redundou num modelo de ocupação urbana bastante polarizado e desigual. Entretanto, a partir dos anos 80 uma nova lógica se impôs, com aumentos crescentes do peso dos setores terciário e quaternário na economia. $\mathrm{O}$ modelo espacial daí decorrente foi menos polarizador que o primeiro, causando reflexos importantes no uso do solo, na divisão socioespacial do trabalho e, conseqüentemente, no fluxo da população.

Desde a década de 70, o Brasil e São Paulo, em particular, vêm assistindo a um crescente aumento no percentual de empregos gerados pelo setor terciário da economia. Em 1985, o setor de comércio e serviços respondia, no Brasil, por $49 \%$ da população economicamente ativa (PEA), e no município de São Paulo essa taxa alcançava 60\% (Sempla, 1990).

A esse quadro soma-se a consolidação de São Paulo como o grande centro financeiro nacional, fato extremamente recente que é um dos elementos-chave na sua constituição como metrópole transacional. Deve-se observar que entre 1980 e 1985 a participação das instituições financeiras no PIB do Estado de São Paulo cresceu de 6,5\% para $20 \%$ (www.seade.gov.br).

Não obstante o crescimento significativo no setor de serviços, o peso da atividade industrial ainda se mantém bastante expressivo na capital paulista, em especial quando comparada com o resto do país. Algumas interpretações, entretanto, partindo da observação da diminuição do peso da capital no Valor de Transformação Industrial (VTI), ${ }^{1}$ chegam à conclusão de que teria ocorrido um "esvaziamento industrial" na capital paulista, constatação que, exatamente por ser bastante genérica, precisa ser melhor analisada. Essa contextualização será realizada tomando como referência dois aspectos: a atual lógica da conformação da Região Metropolitana e seu entorno, e a qualificação do parque industrial que permanece na capital.

$\mathrm{Na}$ verdade, o que ocorre não é uma simples saída de indústrias da capital, mas, graças a fluxos imateriais, em grande parte devidos ao maior controle da informação gerencial a distância, existe a possibilidade de um espraiamento da Região Metropolitana de São Paulo. Pois, de fato, não se trata de uma "transferência" linear do centro econômico e industrial da Capital para o Interior (de forma análoga ao que havia ocorrido na transferência do Rio de Janeiro para São Paulo como a grande metrópole nacional). Em síntese, a saída de plantas industriais do território paulistano associa-se à sua consolidação como metrópole transacional, e se faz em função dela, formando-se assim uma região metropolitana desconcentrada. 
De fato, nesse movimento de desconcentração industrial, a saída das indústrias parece ter ocorrido, sem deixar de considerar a já descrita diminuição do peso do VTI, em virtude de outro elemento associado a esse processo de "metropolização" que é um fato novo: a cisão entre a gestão e a produção. Essa cisão se torna possível graças à tecnologia de informação, em especial nas telecomunicações, e à informatização. Não há como se falar em cisão entre gestão e produção sem a possibilidade da informática, das redes de fibra ótica, etc.

Aquela desconcentração das empresas passa a ser funcional, mas o centro de poder se mantém na capital e desenha-se, na verdade, não uma superação da capital paulista pelas cidades médias que crescem ao seu redor, mas um processo bastante complexo de relações econômicas/ sociais/políticas/informacionais entre São Paulo e sua Região Metropolitana desconcentrada.

Outro aspecto que merece ser aprofundado é a mudança do perfil do parque industrial que permanece na cidade de São Paulo. Em especial porque, por trás das modificações ocorridas na estrutura territorial de produção, na verdade estão os novos arranjos de concorrência e composição do capital, em que se destacam os setores com alta incorporação tecnológica (Pires, 1995).

Enquanto alguns setores, como metalurgia e indústria têxtil, apresentaram significativas diminuições, outros ramos mais modernos, como indústria eletrônica e química, ao contrário da tendência geral, apresentaram um aumento tanto no número de empresas quanto no de empregos.

Destaca-se, agora, o setor de material elétrico-eletrônico voltado especificamente para a indústria de informática, segundo Scott e Storper (1988) o "setor sintomático central" de todo o complexo da indústria de alta tecnologia. No município de São Paulo as indústrias de eletrônica vão apresentar um comportamento inverso ao conjunto da indústria, pois neste caso ocorreu uma importante centralização das atividades, e em particular em seu núcleo urbano mais central. Em 1981, a capital concentrava $44,4 \%$ das indústrias de informática no Brasil e $49,3 \%$ dos empregos, chegando em 1992 a 61,6\% das indústrias e a $70,89 \%$ dos empregos no setor (Pires, 1995).

Em síntese, do ponto de vista do seu arranjo industrial, pode-se afirmar que a metrópole de São Paulo assegurou com ampla vantagem sua supremacia. Quando houve saída de plantas industriais, a maioria se dirigiu para regiões do entorno da metrópole estreitamente vinculadas a ela, configurando o que se pode denominar de "desconcentração funcional”. E quando as plantas industriais se espa- lharam, um processo inverso ocorreu na gestão das unidades com a centralização crescente no município de São Paulo e um crescimento das indústrias com expressiva incorporação tecnológica, as quais, ao contrário de outros ramos, permanecem na cidade, demandando trabalhadores capacitados.

A preocupação com as políticas públicas de saúde faz surgir uma das questões possíveis que é sua relação com a nova configuração do espaço produtivo e do mercado de trabalho. Isso adquire relevância pela conformação do sistema de proteção social brasileiro que, em especial até a Constituição de 1988, se pautava numa fragmentação bastante clara entre os trabalhadores inseridos no mercado formal e o restante da população. No entanto, mesmo depois da implantação do SUS, novas formas de rupturas podem ser identificadas, em especial no acesso ao sistema de saúde supletivo dos convênios, que é particularmente vinculado à inserção no mercado de trabalho formal. Só na RMSP, segundo a Fundação Seade, cerca de $44 \%$ da população se utilizou desse setor em 1994. Soma-se a isso o fato de a rede pública de saúde ter se construído voltada para as populações não-inseridas ou inseridas marginalmente no mercado de trabalho, em especial mulheres e crianças. Daí uma certa dificuldade em incorporar aqueles segmentos populacionais que não conseguiram manter sua inserção no mercado de trabalho formal, com a diminuição do peso do setor secundário em detrimento do terciário $\mathrm{e}$ do quaternário. Ou seja, apenas as alterações na configuração do espaço produtivo paulista implicam, por si só, novas situações para as políticas públicas de saúde.

A consolidação de São Paulo como a metrópole global, transacional brasileira impõe novos desafios na implementação de políticas de saúde que, partindo da concepção de saúde como um direito social, persigam a eqüidade. Não só aumentam as desigualdades socioespaciais e as distâncias a serem percorridas entre "o melhor e o pior", como se está diante de um quadro urbano bastante complexo, em que as lógicas do fluxo da população, do capital e das informações não respeitam os limites administrativos municipais. É essa lógica que será abordada a seguir, tomando-se por referência o fluxo da população em busca de atenção à saúde na RMSP.

\section{O FLUXO DA POPULAÇÃO EM BUSCA DE ATENÇÃO À SAÚDE: UMA DINÂMICA MUNICIPAL OU METROPOLITANA?}

É importante a discussão sobre os fluxos, ${ }^{2}$ pois é em torno deles que a sociedade atual se articula; são fluxos 
de capital, de informação e de tecnologia. Entretanto, como afirma Castells (1999:436), "Fluxos não representam apenas um elemento da organização social: são a expressão dos processos que dominam nossa vida econômica, política e simbólica".

O objetivo aqui é identificar o fluxo da população da RMSP em busca de atenção à saúde, definindo-se qual a lógica de deslocamento intermunicipal que se estabelece.

Para tanto, uma das possibilidades metodológicas reside na utilização dos dados da Pesquisa Origem-Destino (OD), de periodicidade decenal e uma importante referência para os estudos da RMSP. A OD de 1977 foi realizada pela Emplasa (Empresa Metropolitana de Planejamento da Grande São Paulo) e as subseqüentes, pelo Metrô (Diretoria de Planejamento e Expansão dos Transportes Metropolitanos). O conjunto das pesquisas OD se mostrou capaz de fornecer informações relevantes sobre as características socioeconômicas da população, a localização das atividades urbanas e do padrão de mobilidade (fluxo) dessa mesma população.

Para analisar o fluxo da população em busca de atenção à saúde em 1987 e 1997, mantendo-se como referência os fluxos mais gerais da população, procedeu-se a uma tabulação e análise especial dos dados das duas últimas ODs.

Em 1997, foram feitas diariamente 31.432 .000 viagens na RMSP, 1.200.000 viagens por motivo de saúde. Entre 1987 e 1997, as viagens por motivo de saúde (VPMS) mantiveram percentuais constantes em relação às viagens totais (VT) na faixa de $4 \%$. Praticamente não ocorreu variação no índice de viagens por 100 mil habitantes, que se manteve por volta de 3.500 VPMS/100 mil habitantes. ${ }^{3}$ Sem dúvida, o número de pessoas que se locomovem por motivo de saúde é bastante significativo, correspondendo a cerca de $600 \mathrm{mil}$, uma vez que o deslocamento de uma pessoa inclui, em sua maioria, duas viagens (ida e volta), o que equivale a se imaginar uma cidade inteira de porte médio - como Osasco - se movimentando diariamente.

Uma das questões colocadas diante do fluxo estabelecido nas VPMS reside em cotejá-lo com as políticas de saúde implementadas no período 1987-1997. O recorte salientado refere-se à análise da capacidade dos municípios da RMSP para reter em seus territórios as VPMS neles originadas.

Essa opção decorre da constatação do peso dos processos de municipalização nas políticas públicas de saúde estabelecidas nesse período. Uma das diretrizes foi a adscrição da clientela tendo como referência a base municipal, e as experiências de gestão intermunicipal da saúde, sob a forma de consórcios, foram e são ainda bastante incipientes e raras. ${ }^{4}$
Mesmo considerando-se que uma significativa parcela da população da RMSP $(44,0 \%)$ possui convênio médico, ${ }^{5}$ seria previsível que a execução das políticas supracitadas se refletisse em um aumento da capacidade do município de reter as suas VPMS; ou seja, seria possível identificar um padrão de alteração no fluxo das VPMS entre $1987 \mathrm{e}$ 1997, provavelmente um aumento das VPMS retidas e uma diminuição da atração para a capital.

O Mapa 1 apresenta o panorama encontrado em 1987, registrando poucos municípios que retêm mais de $90 \%$ das suas VPMS. Em 1997, como pode ser visto no Mapa 2, ocorreu o inverso do que se previa: apenas os municípios de Cotia e São Paulo mantiveram retenção superior a $90 \%$ das suas VPMS. Uma primeira constatação seria a ocorrência de uma diminuição da capacidade de retenção dos municípios entre 1987 e 1997, que parece imediatamente paradoxal com as lógicas das políticas de saúde do período.

Entretanto, é importante qualificar a existência de dois padrões distintos naqueles municípios que apresentam percentuais elevados de retenção: pode existir realmente a possibilidade de se obter a atenção desejada no próprio município, ou pode-se estar diante de um índice de mobilidade muito baixo e uma demanda bastante reprimida. Para buscar evidenciar ambas as possibilidades compara-se o número de deslocamento pela população, padronizando novamente para 100 mil habitantes. Assim, enquanto São Paulo apresenta um índice de 4.140 viagens por $100 \mathrm{mil}$ habitantes, esse índice diminui para 3.074 em Mogi das Cruzes, 2.405 em Cotia, 1.404 em Embu-Guaçu e 843 em Juquitiba, todos municípios com alto grau de retenção em 1987.

De qualquer forma, uma parte considerável dos municípios da RMSP não consegue, seja em 1987 ou em 1997, fixar as VPMS em seus territórios. Exceto a capital, a escala municipal parece não ser suficiente, na RMSP, para desenhar o fluxo da busca de atenção à saúde.

Não obstante, quando se muda a escala de análise e se opta pela escala metropolitana tomando-se como referência as sub-regiões (Mapa 3), pode-se observar um outro fluxo, detalhado na Tabela 1. Com exceção da sub-região sudoeste, as demais retiveram percentuais superiores a $75 \%$ das VPMS originadas nos municípios que as compõem. A sub-região sudeste foi a que mais atraiu as VPMS nela originadas e registrou a menor atração para a capital. Devese observar, no entanto, que as VPMS foram atraídas para determinados municípios que funcionam como pólo de atração - Guarulhos, Osaco, Mogi das Cruzes, São Bernardo do Campo e Santo André. 
MAPA 1

Percentual de Retenção das Viagens por Motivos de Saúde no Município de Origem Região Metropolitana de São Paulo - 1987

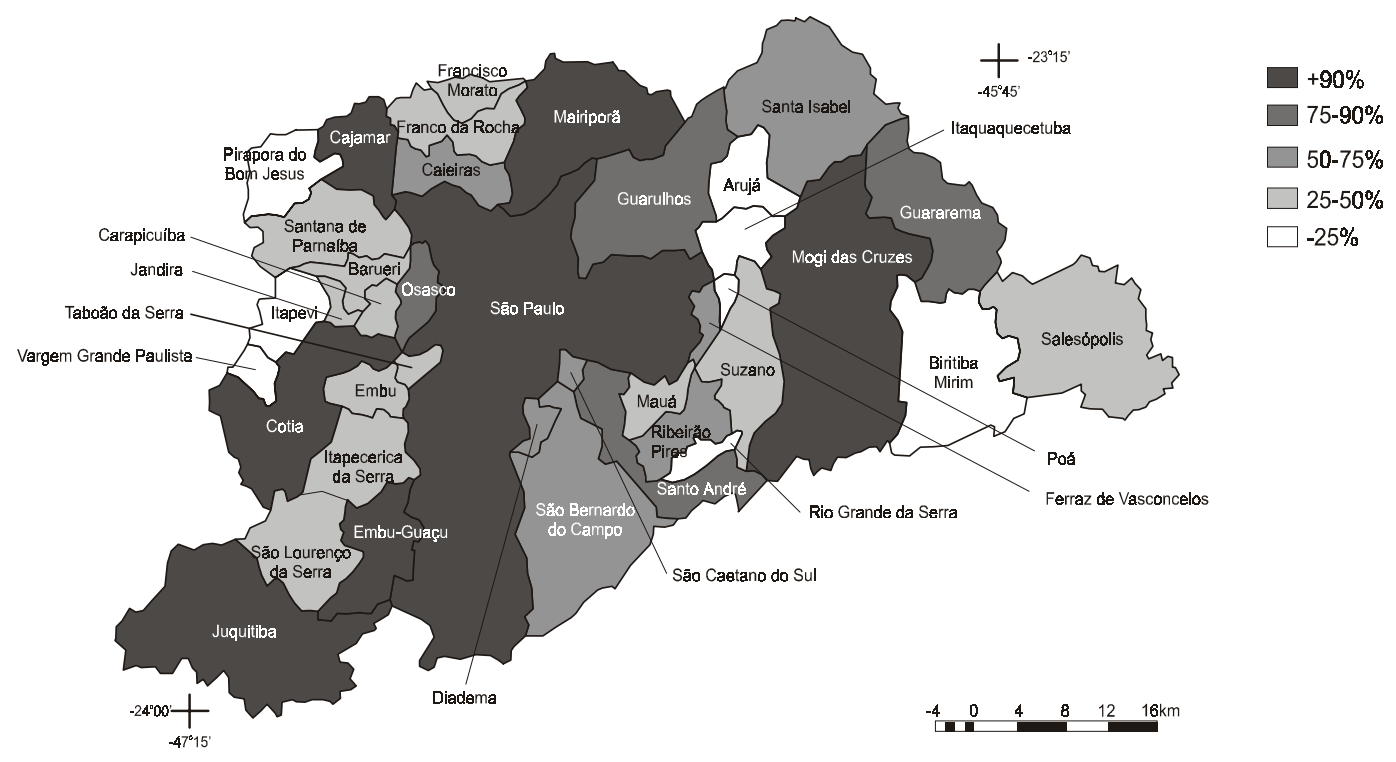

Fonte: Bousquat, 2000.

MAPA 2

Percentual de Retenção das Viagens por Motivos de Saúde no Município de Origem Região Metropolitana de São Paulo - 1997

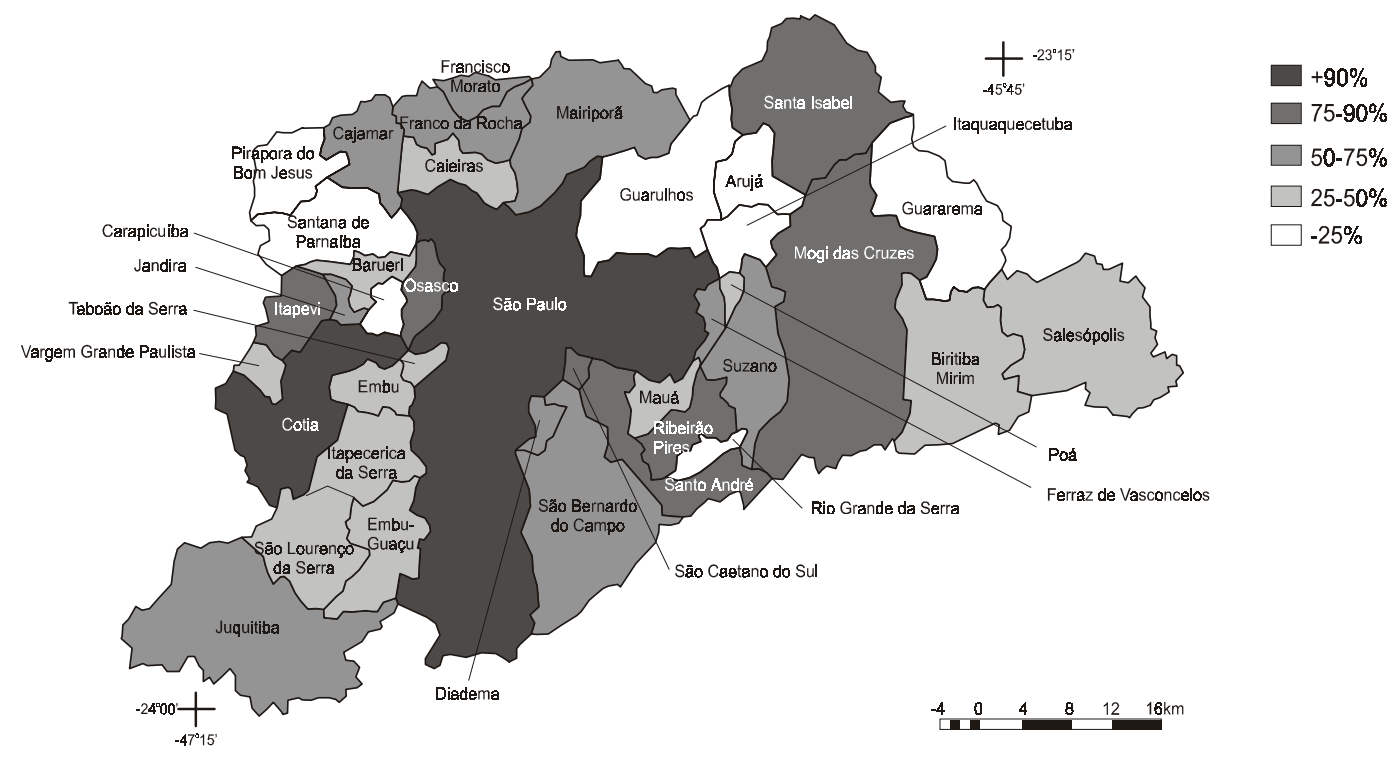

Fonte: Bousquat, 2000. 
MAPA 3

Sub-Regiões Metropolitanas

Região Metropolitana de São Paulo - 1997

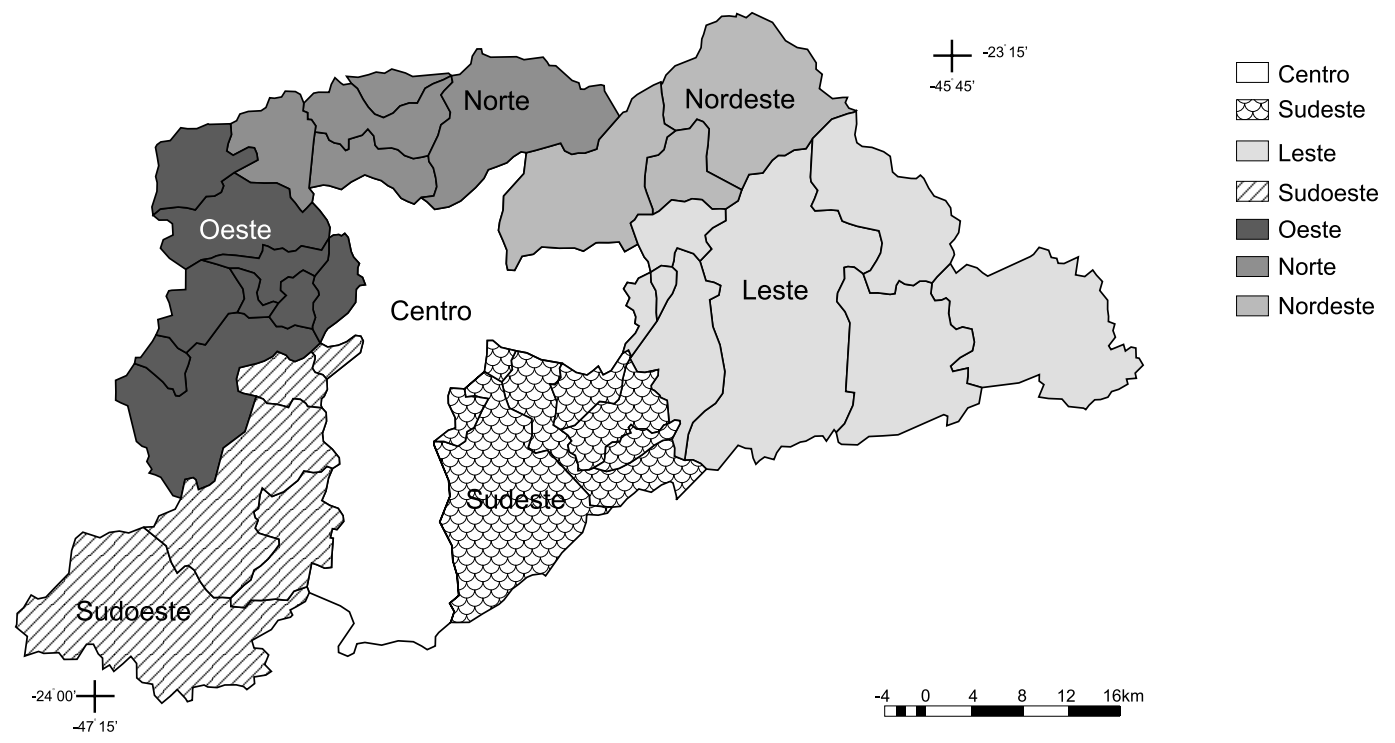

Fonte: Metrô, 1998.

TABELA 1

Viagens por Motivo de Saúde, por Local de Atração, segundo Sub-Regiões Metropolitanas

Região Metropolitana de São Paulo - 1987-1997

\begin{tabular}{|c|c|c|c|c|c|c|}
\hline \multirow{2}{*}{$\begin{array}{l}\text { Sub-Região } \\
\text { Metropolitana }\end{array}$} & \multicolumn{3}{|c|}{1987} & \multicolumn{3}{|c|}{1997} \\
\hline & $\begin{array}{c}\text { Viagens } \\
\text { Atraídas para } \\
\text { a Capital (\%) }\end{array}$ & $\begin{array}{l}\text { Viagens na } \\
\text { Região } \\
(\%)\end{array}$ & Pólo Regional & $\begin{array}{c}\text { Viagens } \\
\text { Atraídas para } \\
\text { a Capital (\%) }\end{array}$ & $\begin{array}{c}\text { Viagens na } \\
\text { Região } \\
(\%)\end{array}$ & Pólo Regional \\
\hline Norte & 22,0 & 76,9 & & 29,6 & 63,0 & \\
\hline Nordeste & 21,2 & 78,8 & Guarulhos $(74,5 \%)$ & 20,3 & 73,0 & Guarulhos $(70,0 \%)$ \\
\hline Leste & 14,0 & 80,0 & Mogi das Cruzes $(42,8 \%)$ & 14,5 & 82,1 & Mogi das Cruzes $(47,3 \%)$ \\
\hline Sudeste & 11,7 & 88,3 & $\begin{array}{l}\text { Santo André }(32,0 \%) \\
\text { São Bernardo }(28,5 \%)\end{array}$ & 12,8 & 87,2 & $\begin{array}{l}\text { Santo André }(36,2 \%) \\
\text { São Bernardo }(26,5 \%)\end{array}$ \\
\hline Sudoeste & 51,5 & 43,0 & & 49,7 & 47,4 & \\
\hline Oeste & 22,2 & 77,0 & Osasco $(51,3 \%)$ & 16,0 & 83,1 & Osasco $(56,0 \%)$ \\
\hline
\end{tabular}

Fonte: Bousquat, 2000.

A capital (sub-região metropolitana centro) não só reteve $96,1 \%$ das VPMS originadas em seu território, mas funcionou como o mais importante pólo de atração das VPMS originadas no conjunto da RMSP.

Assim, as sub-regiões metropolitanas revelaram-se capazes, exceto a sub-região sudoeste, de reter a grande maioria das VPMS originadas em seu próprio território. $\mathrm{Na}$ verdade, desenharam-se lógicas de deslocamentos regionais e não municipais, mas sempre mantendo um fluxo com a capital.
A seguir, um detalhamento das dinâmicas da sub-região metropolitana sudeste, a região do $\mathrm{ABC}$, uma região que reteve o maior número de VPMS, mas desta vez salientando a dinâmica de utilização dos serviços.

\section{O ABC E OS SERVIÇOS DE SAÚDE}

$\mathrm{O} A B C$, uma região com cerca de 2 milhões de habitantes, congrega sete municípios (Santo André, São Bernardo do Campo, São Caetano do Sul, Diadema, Mauá, 
Ribeirão Pires e Rio Grande da Serra) e reúne uma série de contradições, fruto de um modelo de desenvolvimento socioeconômico, político e cultural que conformou uma região com "identidade própria", ligada, todavia, ao processo histórico de conformação socioespacial da capital.

Ao analisar especificamente o desenvolvimento das políticas de saúde na região, há uma presença bastante importante do setor privado de saúde, pois o setor público passou a ter nova configuração no seu padrão de atenção à saúde somente a partir do processo de descentralização, com a Constituição de 1988.

Essa nova configuração do modelo de atenção à saúde, portanto, coincide com a mudança do perfil econômico da região, em consonância com o que aconteceu no conjunto da RMSP, descrito anteriormente, no qual se somam a ampliação do setor de serviços, a escassez do emprego, o desemprego, entre outros, num processo que causou impacto ao setor de saúde, pois ampliou a demanda ao setor público de um contingente populacional que perdeu o direito aos convênios médicos.

Para ilustrar essa situação foram utilizados os parâmetros das condições locais da estrutura de serviços assistenciais de saúde (ambulatorial e hospitalar), a produção dos serviços realizados e a dinâmica intermunicipal de utilização dos hospitais públicos na região.

De certa forma, com a implantação do SUS na região, verificou-se uma expansão dos serviços nos municípios do $\mathrm{ABC},{ }^{6}$ principalmente à custa da atenção ambulatorial, permanecendo um impasse sobre o atendimento especia- lizado ambulatorial e o hospitalar. Mesmo nesse caso foi possível identificar uma ampliação na oferta de leitos públicos na região (Nascimento, 2000), e pode ser mais um elemento que explique a atração de VPMS para a capital, apontada anteriormente.

A partir da análise da produção ambulatorial, apesar da grande dificuldade na disponibilidade de dados, em especial pelas constantes mudanças nos procedimentos e nos registros das informações, pode-se evidenciar as disparidades encontradas na região. O município de Santo André foi o que incorporou o maior grau de tecnologia, enquanto no outro extremo estava Rio Grande da Serra, com capacidade apenas para ofertar serviços de atendimento básico à saúde. Embora Diadema, Mauá, São Bernardo do Campo e São Caetano do Sul apresentassem valores per capita elevados nos gastos com a saúde, os procedimentos realizados concentraram-se proporcionalmente na atenção de menor custo, ou seja, na atenção básica. Os dados disponíveis, entretanto, são insuficientes para uma análise mais precisa sobre a modalidade ambulatorial na região, apenas indicando uma situação muito desigual entre os municípios (Nascimento, 2000).

Ao analisar a rede hospitalar pública verificou-se que, no início da implantação do SUS, apenas os municípios de Mauá, Santo André e São Bernardo do Campo possuíam leitos públicos, embora funcionando precariamente. Nos anos seguintes à implantação observou-se um incremento no número de leitos na região. Ao lado disso, houve diminuição do número de leitos privados na região como pode ser verificado na Tabela 2.

TABELA 2

Evolução no Número de Leitos Gerais (1)

Municípios do Grande ABC - 1990-1997

\begin{tabular}{|c|c|c|c|c|c|c|c|c|c|c|c|c|}
\hline \multirow{3}{*}{ Municípios } & \multicolumn{4}{|c|}{ Hospitais Públicos } & \multicolumn{4}{|c|}{ Hospitais Privados } & \multirow{2}{*}{\multicolumn{2}{|c|}{$\begin{array}{c}\text { Hospitais } \\
\text { Universitários }\end{array}$}} & \multirow{2}{*}{\multicolumn{2}{|c|}{$\begin{array}{l}\text { Número de Leitos } \\
\text { per capita }\end{array}$}} \\
\hline & \multicolumn{2}{|c|}{ Estadual } & \multicolumn{2}{|c|}{ Municipal } & \multicolumn{2}{|c|}{ Lucrativo } & \multicolumn{2}{|c|}{ Não-Lucrativo } & & & & \\
\hline & 1990 & 1997 & 1990 & 1997 & 1990 & 1997 & 1990 & 1997 & 1990 & 1997 & 1990 & 1997 \\
\hline Total & 200 & 0 & 226 & 737 & 3.004 & 2.691 & 864 & 643 & 56 & 64 & 2,1 & 1,7 \\
\hline Santo André & 0 & 0 & 114 & 172 & 976 & 971 & 203 & 76 & 0 & 0 & 2,1 & 1,9 \\
\hline São Bernardo do Campo & 0 & 0 & 0 & 51 & 1.069 & 1.105 & 0 & 0 & 56 & 64 & 2,8 & 1,7 \\
\hline São Caetano do Sul & 0 & 0 & 112 & 103 & 157 & 172 & 495 & 354 & 0 & 0 & 5,1 & 4,7 \\
\hline Diadema & 0 & 0 & 0 & 221 & 426 & 275 & 0 & 0 & 0 & 0 & 1,4 & 1,5 \\
\hline Mauá & 200 & 0 & 0 & 160 & 246 & 68 & 110 & 113 & 0 & 0 & 1,9 & 0,9 \\
\hline Ribeirão Pires & 0 & 0 & 0 & 30 & 130 & 100 & 0 & 0 & 0 & 0 & 1,6 & 1,2 \\
\hline Rio Grande da Serra & 0 & 0 & 0 & 0 & 0 & 0 & 0 & 0 & 0 & 0 & 0 & 0 \\
\hline
\end{tabular}

Fonte: CAH-106/ Datasus/Fundação IBGE.

(1) Não foram considerados os leitos psiquiátricos. 
Em termos regionais, pode-se afirmar, portanto, que a oferta de serviços públicos de saúde aumentou consideravelmente, como também se diversificou o espectro de ações, procurando atender às distintas demandas desse complexo setor. Esse perfil, no entanto, manteve um nítido padrão intra-regional de absorção da demanda por serviços de saúde, como será visto a seguir, confirmando a lógica de funcionamento metropolitana apontada na seção precedente.

\section{A Dinâmica de Utilização dos Serviços}

Por meio da informação oferecida pelo Datasus sobre a origem do paciente submetido à internação hospitalar pela Guia de Autorização de Internação Hospitalar (AIH), verifica-se que as internações ocorridas no $\mathrm{ABC}$ não obedeceram a uma lógica racional de referência hospitalar pactuada previamente nos termos dos parâmetros de necessidade versus oferta de serviços, afirmação possível

\section{GRÁFICO 1}

Internações, por Especialidade, segundo Origem e Destino do Paciente

Municípios do Grande ABC - 1998

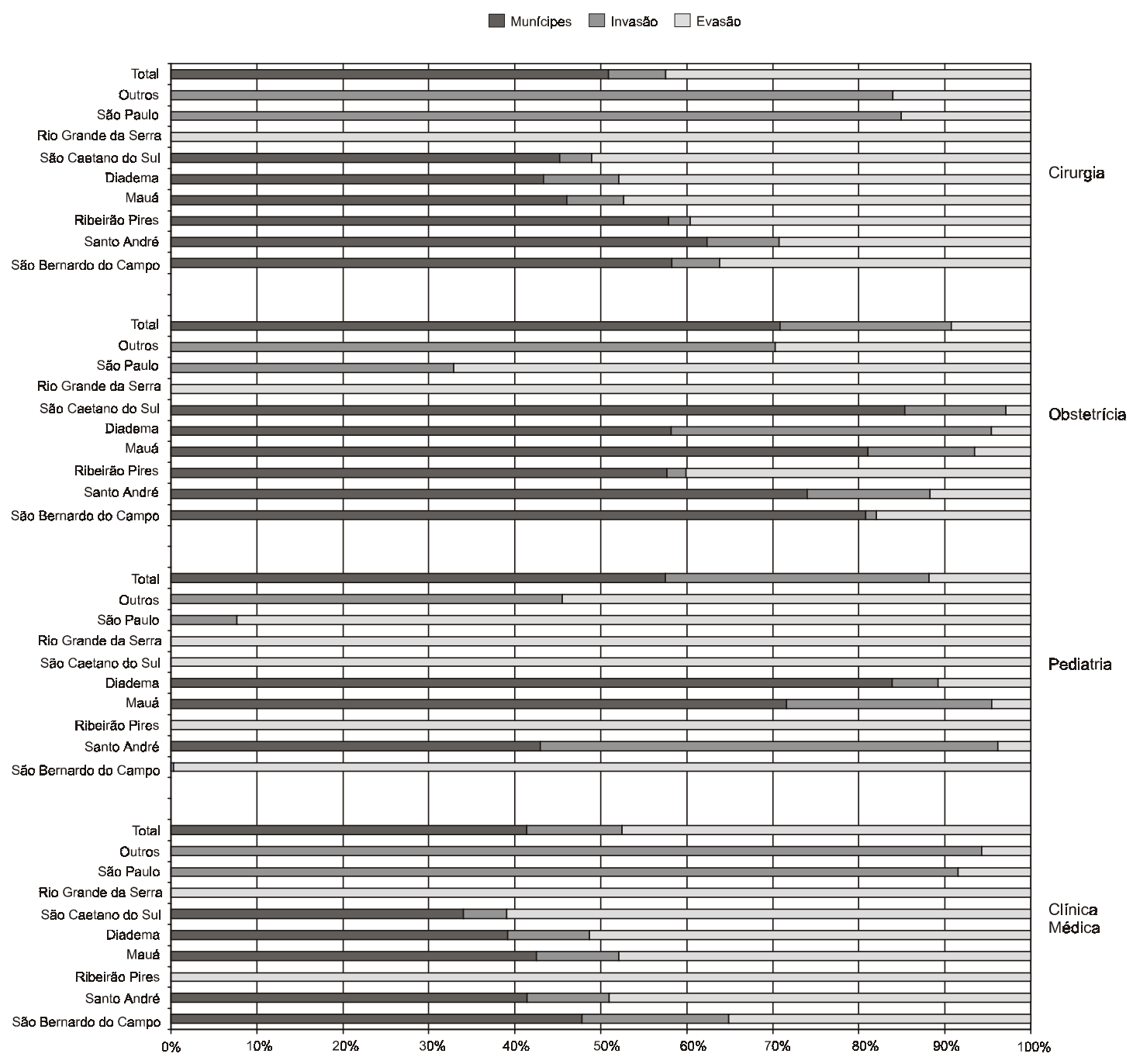

Fonte: Datasus/AIH 
pelo modo de utilização desses serviços, porque obedecem a uma lógica metropolitana, ultrapassando os limites territoriais municipais.

Detendo-se no fluxo de usuários em termos intra-regionais (Gráfico 1), nota-se que os municípios de Santo André e Mauá foram os que mais atenderam a uma gama diversificada de necessidades hospitalares (obstetrícia, clínica médica, clínica cirúrgica e pediatria), absorvendo a clientela de praticamente todos os municípios da região, inclusive de São Paulo. Talvez a explicação para isso esteja na história dos hospitais - Municipal de Santo André e Nardine, em Mauá -, que já apresentavam características regionais antes da implantação efetiva do SUS. Nos demais municípios, registrou-se uma invasão menor, justamente por terem concebido seus serviços dentro da lógica do SUS - Municipal. Todavia, registra-se um intenso desgaste das Secretarias Municipais de Santo André e Mauá, por não terem conseguido reverter essa situação que compromete acentuadamente sua governabilidade, uma vez que o aumento dos gastos com a saúde tem sido inversamente proporcional à satisfação dos seus munícipes. Os prefeitos e secretários de saúde dessas cidades alegam que essa invasão de munícipes de outras cidades impede que haja um melhor atendimento à população local, porquanto mais de $50 \%$ dos recursos destinados à saúde acabam sendo absorvidos pela assistência hospitalar, a modalidade assistencial em que a invasão se faz mais presente. Como conseqüência, os munícipes dessas cidades ficam descontentes porque ao necessitar de uma vaga para internação são colocados na mesma condição dos pacientes de outras cidades e submetidos a serviços com condições adversas, como prontos-socorros lotados, internações em macas nos corredores, transferência para outros hospitais da Região Metropolitana, etc., comprometendo a "imagem" do governo municipal. Isso gera uma tensão muito grande entre os municípios da região, avaliada pelos gestores municipais de saúde como de difícil solução a curto prazo (Nascimento, 2000).

A perspectiva da lógica metropolitana paulista contribui com aspectos relevantes para o processo de formulação e implementação das políticas públicas de corte social, neste caso as de saúde. Não é possível pensar em atendimento equânime das necessidades de saúde na metrópole, sem incorporar as questões desencadeadas por seu processo de conformação espacial e suas dinâmicas social, econômica e política aí estabelecidas.

\section{NOTAS}

E-mail das autoras: aylenebousquat@uol.com.bre javan@uol.com.br

Este artigo é um dos resultados das teses de doutorado de Bousquat (2000) e de Nascimento (2000).

Deve-se ressaltar a importância da orientação da Profa. Dra. Amélia Cohn, sem a qual teria sido impossível a elaboração das teses, e da colaboração da Diretoria de Planejamento e Expansão dos Transportes Metropolitanos do Metrô, que cedeu a Tabulação Especial da Pesquisa Origem-Destino.

1. Em 1960 a capital respondia por cerca de 60\% do VTI do Estado de São Paulo, valores que diminuem progressivamente chegando em cerca de $30 \%$ em 1985 . Fonte: FIBGE, Censos Industriais 1960-1985.

2. Assume-se aqui a definição de fluxos proposta por Castells (1999:436): "as seqüências intencionais, repetitivas e programáveis de intercâmbio e interação entre posições fisicamente desarticuladas, mantidas por atores sociais nas estruturas econômica, política e simbólica da sociedade".

3. Os índices foram: 3614,5 em 1987 e 3525,5 em 1997.

4. Na área de saúde houve um consórcio na década de 80 entre as cidades de Ferraz de Vasconcelos, Itaquaquecetuba e Poá, que não perdurou até os anos 90.

5. Fonte: http://www.seade.gov.br - Pesquisa de Condições de Vida, 1994.

6. Entre 1988 e 1998 o número de unidades básicas de saúde na região passou de 118 para 190 (Nascimento, 2000).

\section{REFERÊNCIAS BIBLIOGRÁFICAS}

BOUSQUAT, A. Para a incorporação do espaço no estudo da saúde. Tese de Doutorado. São Paulo, Departamento de Medicina Preventiva, FMUSP, 2000.

CASTELlS, M. A sociedade em rede. São Paulo, Paz e Terra, 1999.

FUNDAÇÃO IBGE. Censos industriais. Brasília, FIBGE, 1960-1980.

LENCIONI, S. "Reestruturação urbano-industrial no Estado de São Paulo: a região da metrópole desconcentrada". In: SANTOS, M.; SOUZA, M.A. e SILVEIRA, M.L. Território: globalização e fragmentação. São Paulo, Hucitec/Anpur, 1996.

METRÔ. Pesquisa origem destino. Relatório Final, São Paulo, 1987. lo, 1998 .

$$
\text { . Pesquisa origem destino 1997. Síntese das Informações, São Pau- }
$$

NASCIMENTO, V. SUS, gestão pública e sistema federativo no Brasil. Tese de Doutorado. São Paulo, Departamento de Medicina Preventiva, FMUSP, 2000.

PIRES, F. Reestruturação industrial e alta tecnologia no Brasil: as indústrias de informática em São Paulo. Tese de Doutorado. Departamento de Geografia, FFLCH/USP, 1995.

SANTOS, M. O espaço do cidadão. São Paulo, Nobel, 1993a.

$$
\text { . A urbanização brasileira. São Paulo, Hucitec, } 1993 \text { b. }
$$

Por uma economia política da cidade - o caso de São Paulo. São Paulo, Hucitec/Educ, 1994.

SCOTT, A. e STORPER, M. "Indústria de alta tecnologia e desenvolvimento regional: uma ccrítica e reconstrução teórica”. Espaço \& Debates. São Paulo, n. 25,1988

SEMPLA - SECRETARIA MUNICIPAL DE PLANEJAMENTO. São Paulo: crise e mudança. São Paulo, Brasiliense, 1990. 